\title{
VARIÁVEIS CONTINGENCIAIS E SISTEMAS DE CONTROLE GERENCIAL PREDOMINANTES EM UMA REDE DE SUPERMERCADOS DO BRASIL ${ }^{1}$
}

\author{
CONTINGENCY VARIABLES AND PREDOMINANT MANAGEMENT CONTROL
}

SYSTEMS IN A SUPERMARKET NETWORK IN BRAZIL

\section{Lara Fabiana Dallabona ${ }^{2}$}

Professora efetiva da Universidade do Estado de Santa Catarina

Doutora em Ciências Contábeis e Administração pela FURB

lara.dallabona@udesc.br

\author{
Leonardo Tomasoni Nardelli \\ Graduado em Ciências Contábeis pela Universidade do Estado de Santa Catarina \\ leonardonardelli94@hotmail.com \\ Ana Rita Venzon Fernandes \\ Graduanda em Ciências Contábeis pela Universidade do Estado de Santa Catarina \\ anaritavenzon@gmail.com
}

\begin{abstract}
RESUMO
Objetivo: Identificar a percepção dos líderes em relação às variáveis contingenciais e os Sistemas de Controle Gerencial predominantes em uma rede de supermercados do Brasil.

Fundamento: A Teoria da Contingência propõe que as estruturas organizacionais e os processos eficientes dependem do contexto da organização (Waterhouse \& Tiessen, 1978), o que sugere que variáveis contingenciais, como o tamanho, ambiente, estrutura e outras, influenciam o desempenho e a utilização dos Sistemas de Controle Gerencial.
\end{abstract}

Método: Trata-se de um estudo quantitativo com utilização da técnica de consenso, pesquisa descritiva e de levantamento, envolvendo uma amostra de 126 líderes, com cargos de diretores, gerentes, supervisores e outras funções com poder de decisão nos supermercados pesquisados.

Resultados: Houve predominância da variável contingencial tecnologia, seguida da incerteza ambiental. Os gestores dos supermercados precisam estar atentos a novas tendências, a fim de agilizarem processos e diminuírem custos para serem capazes de fidelizar e atrair novos clientes. Os Sistemas de Controle Gerencial predominantes foram os controles formais. Esses sistemas englobam o orçamento tradicional e métodos de custeio que auxiliam na tomada de decisões.

Contribuições: Por considerar que a Teoria da Contingência existe no contexto da mudança ambiental evolucionária, as organizações eficazes são aquelas capazes de adaptarem-se as variáveis

\footnotetext{
${ }^{1}$ Artigo recebido em: 08/01/2018. Revisado por pares em: 07/05/2018. Reformulado em: 03/10/2018. Recomendado para publicação, após a segunda rodada, em: 03/10/2018 por Adriana F. de Vasconcelos (Editora Adjunta). Publicado em: 25/01/2019. Organização responsável pelo periódico: UFPB

2 Endereço: Rua Dr. Getúlio Vargas, n. 2822, Bela Vista - Ibirama/SC - 89140-000
} 
ambientais (Wright, Kroll \& Parnell, 2007). Estudos envolvendo a Teoria da Contingência se tornam relevantes ao explorar algumas variáveis contingenciais que impactam na gestão organizacional e consequentemente nos SCG, o que faz com que este estudo se torne relevante para a literatura.

Palavras-chave: Variáveis Contingenciais. Sistemas de Controle Gerencial. Supermercados.

\section{ABSTRACT}

Objective: To analyze the leaders perceptions regarding the contingency variables and the Management Control Systems prevalent in a supermarket chain in the South of Brazil.

Background: The Contingency Theory proposes that organizational structures and efficient processes depend on the context of the organization (Waterhouse \& Tiessen, 1978), which suggests that contingency variables, such as size, environment, structure and others, influence performance and the use of Management Control Systems, since, for Simons (1995), SCG are defined as a means for the implementation and success of the strategy.

Method: This is a quantitative study using the consensus technique, descriptive and survey research, involving a sample of 126 leaders, with positions of directors, managers, supervisors, and other activities with decision-making power in the supermarket that have been researched in this paper.

Results: There was a predominance of the contingency variable technology, followed by environmental uncertainty. Supermarket managers need to be alert to new trends in order to streamline processes and lower costs in order to be able to retain and attract new customers. The predominant Management Control Systems were the formal controls. These systems encompass the traditional budget and costing methods that aid in the company's ability to make decisions.

Contributions: Considering that Contingency Theory exists in the context of evolutionary environmental change, the effective organizations are those capable of adapting to environmental variables (Wright, Kroll \& Parnell, 2007). Studies involving the Contingency Theory become relevant when exploring some contingency variables that influence on the organizational management and consequently on the SCG, which makes this study become relevant for the literature.

Keywords: Contingency Variables. Management Control Systems. Supermarkets.

\section{INTRODUÇÃO}

Controle gerencial é entendido como o processo de conduzir organizações em busca de padrões viáveis de atividade em lugares trajados por mudanças (Aguiar et al., 2009). Um sistema de controle gerencial (SCG) pode auxiliar nas escolhas estratégicas de uma organização. Geralmente é utilizado de forma interativa, contribuindo positivamente para orientação de mercado, como empreendedorismo, inovação e aprendizagem organizacional. Com seu uso equilibrado surge a tensão dinâmica, que apesar de negativa, pode contribuir positivamente, mesmo em um ambiente de elevada incerteza ambiental e organizacional (Henry, 2006), pois a tensão dinâmica pode ser exemplificada como a busca por objetivos a longo prazo, sem analisar o curto prazo e ter um controle racional de custos, sem reduzir o processo de inovação, por consequência, as tensões dinâmicas podem estimular o empreendedorismo e a inovação, aumentando os valores da empresa (Oyadomari et al., 2010).

As organizações são sistemas abertos que cautelosamente precisam se adaptar a circunstâncias externas e atender as necessidades internas, conforme preceitua a Teoria da Contingência. Nesse sentido, não existe uma forma específica de organização, pois cada variável ou ambiente pode moldar um estilo diferente. A administração deve preocupar-se em atingir padrões e ajustes 
concretos; fugir da monotonia para conseguir resultados diferentes. Estas são algumas ideias nas quais se baseia a abordagem contingencial de uma organização, estabelecidas como uma perspectiva dominante de análise organizacional moderna (Morgan, 1996).

Em uma organização com um ambiente dinâmico, ou seja, com mudanças constantes, a estrutura orgânica é mais apropriada. Ela caracteriza as organizações como sistemas abertos que se adaptam às variáveis contingenciais ambientais. Inversamente se tem a estrutura mecanicista, que é caracterizada por ser mais fechada, não muito moldável às contingências ambientais. Então, quando uma organização encara um ambiente estável e monótono, a estrutura mecanicista é mais adequada e eficaz (Burns \& Stalker, 1961).

Os sistemas de controle gerenciais são modificativos e dependem de diferentes fatores e variáveis, tais como: tipos de líderes, cultura e características da população. É por isso que os SCG estão atrelados às variáveis contingenciais (Dallabona, 2014) e estas, por sua vez, dependem de cada organização.

Vários fatores influenciam os sistemas gerenciais e o estilo para liderar, como o local, a estrutura, o ambiente, o perfil dos colaboradores, além do porte das empresas. Essas variáveis são praticamente o alicerce, que estipulam metas e a forma de trabalho das organizações.

Alguns pesquisadores têm se especializado nessas variáveis, tais como Burns e Stalker (1961), Fagundes et al. (2010) e Donaldson (2015). As variáveis contingencias podem variar de acordo com o "tamanho" da organização. Empresas que enfrentam baixa incerteza são formadas por estruturas hierárquicas especializadas e centralizadas, enquanto as que enfrentam elevada incerteza são "equipadas" com uma menor especialização e descentralização (basicamente as decisões são tomadas em níveis mais baixos da hierarquia) (Donaldson, 2015).

A variação no ambiente pode ser uma causa necessária para a mudança organizacional. É inquestionável que as previsões sobre a adaptabilidade das organizações nos ambientes em que estão inseridas não podem ser feitas sem conhecimento adequado ou compreensão das condições ou características ambientais subjacentes. Felizmente, toda organização viável tem algum conhecimento, mesmo que incompleto, sobre a natureza do ambiente com o qual ela interage. Por exemplo, a maioria das organizações empresariais sabe quem são seus clientes, fornecedores, concorrentes e financiadores, bem como os sindicatos, agências reguladoras e outras entidades políticas e socioculturais com as quais deve lidar (Ewusi-mensha, 1981).

O sucesso de qualquer organização, pelo menos em termos de satisfazer as exigências ambientais que lhe são impostas, pode depender do grau de compreensão do ambiente (Ewusimensha, 1981). O estado do ambiente com o qual uma organização interage pode ser classificado como controlável, parcialmente controlável e incontrolável, conforme sugerem Ein-Dor e Segev (1978), quando classificam as variáveis organizacionais internas que afetam o sucesso de um SCG.

Os fatores ambientais têm sido invocados para explicar as diferenças na utilização das informações contábeis. Khandwalla (1972) examinou como o tipo de concorrência enfrentado por uma empresa afetava o uso do controle gerencial. Concluiu que quanto maior a concorrência, maior era a sofisticação dos sistemas contábeis e de controle, além de outros tipos de competição, como preço e marketing.

Avanços significativos vêm sendo apresentados no campo de pesquisa sobre as variáveis contingencias, uma vez que elas são capazes de regular toda a sistemática de uma organização, a partir de mínimos detalhes (Morgan, 1996). Existem estudos relacionados a sistemas de controle gerencial e Teoria da Contingência (Gordon \& Narayanan, 1984; Hoque, 2004; Molinari \& Guerreiro, 2004; Gerdin, 2005; Henry, 2006; Junqueira, 2010; Fagundes et al. 2010), entretanto estudos que abrangem esses dois temas carecem de continuidade de análises empíricas em diferentes ramos de negócios. Assim emerge a pergunta que norteia o desenvolvimento do estudo: Qual a percepção dos líderes sobre as variáveis contingenciais e os Sistemas de Controle Gerencial predominantes 
em uma rede de supermercados do Brasil? O objetivo do trabalho, portanto, é identificar a percepção dos líderes em relação às variáveis contingenciais e os Sistemas de Controle Gerencial predominantes em uma rede de supermercados do Brasil.

Observou-se incipiência no desenvolvimento de estudos nacionais e internacionais que analisam a percepção de líderes sobre contingências internas e externas, bem como sobre sistemas gerenciais com enfoque para supermercados, o que demonstra contribuição teórica do estudo ao apontar especificidades do ambiente investigado em relação às variáveis contingenciais que impactam os sistemas de controle gerencial, para que estudos futuros possam dar continuidade às investigações e auxiliar no discernimento do tema.

Outra contribuição decorre do fato que líderes que trabalham diretamente com redes supermercadistas possam utilizar o estudo como base para melhorar os processos gerenciais e observar os impactos que algumas variáveis demonstram para a área, a fim de se adequar ao ambiente e melhorar os processos gerenciais, para tomar decisões mais precisas e coerentes.

A pesquisa contribui no campo prático ao fornecer informações aos gestores sobre o impacto que as diferentes variáveis contingenciais podem oferecer na formalização de um desenho específico de SCG, justificando o desenvolvimento do estudo.

\section{REFERENCIAL TEÓRICO}

\subsection{Teoria da Contingência}

A Teoria da Contingência existe no contexto da mudança ambiental evolucionária, sendo assim, as organizações eficazes são aquelas capazes de adaptarem-se às variáveis ambientais. Aquelas que não seguirem as mudanças graduais ficarão obsoletas e perderão espaço (Wright, Kroll \& Parnell, 2007).

Estimar como surgiu a Teoria da Contingência é um tanto difícil, mas segundo Junqueira (2010), sua origem data do final da década de 1950 e início da de 1960, confirmando a elevada intensidade de estudos dos temas iniciados pela Escola Sistêmica. Tal escola parte do pressuposto de que não existem modelos que possam ser adaptados a todas as empresas em todas as situações, já que as mudanças ocorrem nos sistemas em função do impacto de determinados tipos de ocorrências.

Dessa forma, a Teoria da Contingência busca identificar os aspectos específicos de um sistema gerencial associado a determinadas circunstâncias definidas, e demonstrar uma correspondência adequada ao ambiente (Otley, 1980), considerando que a eficácia organizacional depende da capacidade de a empresa se adaptar as mudanças externas e fatores internos (Haldma \& Lääts, 2002).

De acordo com a Teoria da Contingência, a organização possui natureza sistêmica, isto é, suas características organizacionais apresentam uma interação entre si e o ambiente externo (Oliveira, 2008).

Mesmo o termo Teoria da Contingência só tendo sido utilizado em 1967, é possível citar o estudo Management and Technology de Woodward (1958) como pioneiro na abordagem contingencial, no qual foi realizada uma pesquisa com 100 indústrias inglesas, verificando-se que as variáveis estruturais estavam ligadas à tecnologia dos processos produtivos dessas empresas. Dessa forma, Kewley (1966) e Junqueira (2010) salientam que a adequação entre estrutura organizacional e tecnologia empregada conduz a um desempenho superior.

Molinari e Guerreiro (2004, p. 3) defendem que "a Teoria da Contingência é uma perspectiva teórica do comportamento organizacional que enfatiza a maneira pela qual as variáveis contingencias, como a tecnologia e pressões ambientais, afetam o desenvolvimento e funcionamento das organizações". Verifica-se, assim, que o esforço gerencialista da Teoria da Contingência no sentido 
de responder e atenuar os impactos de fatores internos e externos às organizações proporcionou um balizamento e campo teórico para os fundamentos dos processos de gerenciamento de riscos.

Assim, cabe às empresas adaptarem os processos formais ou informais de gerenciamento de riscos para que variáveis contingencias alheias aos contratos formais ou informais, internos ou externos, sejam devidamente mitigadas (Molinari \& Guerreiro, 2004). As pesquisas que fazem referência à Teoria da Contingência buscam identificar quais são as variáveis influentes nas organizações.

Algumas dessas variáveis contingencias são a incerteza ambiental, estudada por Burns e Stalker (1961), a estratégia, proposta por Chandler (1962), a estrutura, com base em Burns e Stalker (1961), o porte, de acordo com Child (1975), os ciclos de vida organizacional, conforme Greiner (1972), e a tecnologia, proposta por Merchant (1984).

Estruturalmente o mercado é complexo tanto no que se refere ao comportamento do consumidor quanto à identificação de estratégias organizadas pelas empresas. Desta forma, conhecer estrategicamente as preferências dos clientes oportuniza decisões sobre quais práticas gerenciais e estratégicas adotar para obter resultados positivos, a fim de alcançar as metas organizacionais (Veiga-Neto \& Souza, 2012).

Portanto, a variável contingencial incerteza ambiental, na percepção de Chenhall (2003) e Jokipii (2010), deduz que quanto mais hostil e conturbado for o ambiente externo à empresa, maior será a confiança atribuída aos controles formais e aos orçamentos tradicionais, o que sugere que essa variável possa estar diretamente relacionada aos supermercados, pois analisar as preferências e gostos do público externo nem sempre é uma tarefa fácil para as organizações. Outra variável externa que se considera relevante na literatura é a influência do governo e sindicatos de categorias econômicas que regem as obrigações trabalhistas da área direcionados a qualquer tipo de organização.

A variável estratégia, conforme destaca Porter (1994), está relacionada ao posicionamento no mercado em relação à concorrência. Dependendo dos sistemas gerenciais utilizados pelas empresas, os sistemas serão utilizados de diferentes maneiras (Jokipii, 2010), o que pode influenciar, por exemplo, as estratégias adotadas pelos supermercados a fim de se posicionar com destaque no ramo em que atuam.

No que se refere à variável estrutura, pressupõe que esteja relacionada com o ramo supermercadista ao passo que, de acordo com Gerdin (2005), embasado nos estudos de Bruns e Waterhouse (1975) e Merchant (1981, 1984), conforme as organizações e departamentos crescem e se tornam mais complexos, tendem a descentralizar e a implementar uma estratégia de controle mais orientada, envolvendo maior grau de formalização e aumento do uso de padrões formais de comunicação.

No que se refere ao tamanho/porte organizacional, Ezzamel (1990) destaca que organizações maiores tendem a ser mais especializadas, padronizadas e formalizadas em comparação a pequenas organizações. Greiner (1972) já destacava que com o aumento no tamanho das empresas, problemas de coordenação e comunicação se ampliam, novas funções surgem, os níveis da hierarquia se multiplicam e os trabalhos se tornam mais interdependentes.

Quanto à tecnologia, proposta por Merchant (1984), quando o ambiente se torna incerto e complexo, novos empreendimentos tecnológicos podem tornar-se hesitantes por comprometer recursos para a realização de inovações de produtos ou iniciar projetos de P\&D de alto risco $(\mathrm{Li}$, Zhang \& Chan, 2005), porém no setor supermercadista a variável é relevante quanto aos controles de estoques, administrativo e financeiro, pois não se trata de uma empresa de transformação. 


\subsection{Sistemas de Controle Gerencial}

Segundo Gomes (1997), a partir da década de 1950 o tema controle gerencial passou a ser mais estudado, sofrendo uma expansão conceitual. Durante as décadas de 1950 e 1960 o controle gerencial começou a incorporar conhecimentos oriundos de outras áreas, tais como psicologia, sociologia e antropologia, e com isso as pesquisas sobre controle sofreram significativas mudanças.

Os Sistemas de Controle Gerencial englobam sistemas de planejamento, relatórios e procedimentos de monitoramento baseados no uso da informação (Henri, 2006; Hared \& Abdullah, Huque, 2013). Para Langfield-Smith (1997), este conjunto de sistemas deve ser mais amplo, pois a contabilidade gerencial engloba controles baseados em planejamento, acompanhamento de atividades, medição de desempenho e mecanismos de integração, além de descrever processos para influenciar o comportamento organizacional. Nesse sentido, Malmi e Brown (2008) sugerem controles que podem ser trabalhados em conjunto e que possibilitam uma visão mais abrangente das práticas de controle gerencial.

Malmi e Brown (2008) dividem seu modelo de sistema de controle gerencial em cinco grupos: controle de planejamento (planejamento estratégico e planejamento operacional); cibernéticos (orçamentos, controles financeiros, não-financeiros e híbridos); remuneração e recompensa; administrativos (estrutura de governança; estrutura política e planejamento operacional) e culturais (valores). A partir desses grupos, acredita-se que os gerentes operacionais conseguem ter um maior controle sobre as pessoas que estão subordinadas a ele, possibilitando uma visão mais ampla da organização.

Essa visão pode estar relacionada às dimensões dos SCG, as quais são importantes para a definição de estratégias e processos organizacionais, pois possibilitam o controle e substanciam a retroalimentação, considerando que a competição está diretamente relacionada às estratégias e processos inovadores dos negócios (Beuren \& Oro 2014). De acordo com Chenhall et al. (2011) pode-se afirmar que a estratégia de diferenciação e inovação em relação aos produtos se relacionam com os SCG, observando seu papel relacionado as dimensões de redes sociais, cultura e controles formais.

Conforme especificam Chenhall et al. (2011) os controles gerenciais formais quando integrados ao planejamento organizacional e ao orçamento tradicional contribuem para fatores inovadores nas empresas, com a identificação de oportunidades de negócios, bem como a motivação de pessoas envolvidas por meio de critérios de recompensas.

De acordo com Beuren e Oro (2014, p. 290), controles formais "facilitam a inovação por propiciar informações quanto ao andamento da produção, qualidade dos produtos e retorno dos investimentos, evidenciando a necessidade de ajustes periódicos que podem resultar na implementação de estratégias de diferenciação e inovação de produtos".

Pletsch (2015) destaca que os sistemas formais incluem planejamento estratégico e orçamento (Simons, 1987, 1990; Marginson, 2002; Anthony \& Govindarajan, 2008), mensuração de desempenho, alocação de recursos, recompensas a empregados (Simons, 1987, 1991; Anthony \& Govindarajan, 2008), monitoramento do ambiente, análise de concorrência (Simons, 1987, 1991), controle de custos (Simons, 1991; Marginson, 2002), sistemas de recursos humanos, sistemas de planejamento de carreira, sistemas de monitoramento de projetos (Marginson, 2002), alocação de centro de responsabilidade e composição de preço de transferência (Anthony \& Govindarajan, 2008).

O processo de controle necessita de apuração de informações que possibilitem a formação de diretrizes e mensuração do resultado nos mesmos moldes. Em universos caracterizados por mudanças e bastante competitivos é de fundamental importância a existência de informações externas e internas, a fim de facilitar a adaptação estratégica (Gomes, 1997).

Faz-se importante mencionar que quando o assunto envolve os gestores operacionais o controle gerencial assume um caráter mais amplo, sendo necessária uma série de controles utilizados 
para objetivos distintos, devendo considerar, ainda, a diversidade das próprias organizações, o que sugere a utilização de controles trabalhados de forma conjunta, a fim de possibilitar uma visão mais abrangente das práticas de controle gerencial (Malmi \& Brown, 2008).

\section{ASPECTOS METODOLÓGICOS}

Quanto à abordagem do problema, a pesquisa caracteriza-se como quantitativa, pois utilizou estatística descritiva e a técnica de consenso. Este estudo é caracterizado como survey, pois utiliza questionário para análise empírica.

A população envolveu 172 gestores/líderes de uma rede de supermercados do Sul do Brasil. Utilizou-se amostragem por acessibilidade e intencional compreendendo 126 respondentes, o que corresponde a 72,26\% da população, conforme especifica a Tabela 1.

Tabela 1: População e Amostra da pesquisa

\begin{tabular}{l|l|c|c}
\multicolumn{1}{c|}{ Nome } & \multicolumn{1}{c|}{ Cidade } & População & Amostra \\
\hline Supermercado A & Cidade 1 & 20 & 20 \\
Supermercado B & Cidade 2 & 15 & 15 \\
Supermercado C & Cidade 3 & 32 & 22 \\
Supermercado D & Cidade 4 & 37 & 24 \\
Supermercado E & Cidade 5 & 19 & 12 \\
Supermercado F & Cidade 6 & 26 & 14 \\
Supermercado G & Cidade 7 & 23 & 19 \\
\hline Total & & $\mathbf{1 7 2}$ & $\mathbf{1 2 6}$ \\
\hline
\end{tabular}

Fonte: Dados da pesquisa.

A pesquisa foi aplicada de forma presencial pelos pesquisadores nos meses de setembro e outubro de 2016. Para a coleta dos dados, exceto o primeiro bloco de perguntas (características dos respondentes) a técnica utilizada foi o questionário com perguntas fechadas, optando-se por utilizar a escala Likert de 7 (sete) pontos.

O questionário foi estruturado em duas seções. As questões foram elaboradas de acordo com a literatura e adaptadas após aplicação de pré-teste. É relevante destacar que algumas questões foram traduzidas com auxílio de um especialista em língua inglesa, objetivando garantir o real entendimento das palavras e frases.

Quadro 1: Constructo da pesquisa referente às Variáveis Contingenciais

\begin{tabular}{|c|c|c|c|c|}
\hline Variáveis & Subvariáveis & $\begin{array}{l}\text { Operacionalização das subvariá- } \\
\text { veis }\end{array}$ & Medidas & Autores \\
\hline & $\begin{array}{l}\text { Incerteza } \\
\text { Ambiental }\end{array}$ & $\begin{array}{lcr}1 & \text { Ações dos } & \text { fornecedores } \\
2 & \text { Ações dos } & \text { concorrentes } \\
3 & \text { Demanda dos } & \text { clientes } \\
4 & \text { Disponibilidade de crédito/taxas } \\
\text { de } & & \text { juros } \\
5 & \text { Mudanças na } & \text { legislação } \\
\text { 6Globalização } & & \\
7 \text { Momento econômico }\end{array}$ & $\begin{array}{l}\text { Questões (1 a } 7 \text { ) } \\
\text { Escala Likert } 1 \text { a } 7 \\
\text { (fácil de prever - } \\
\text { difícil de prever) }\end{array}$ & $\begin{array}{l}\text { Hoque (2004), } \\
\text { Gordon e Nara- } \\
\text { yanan (1984), } \\
\text { Govindarajan } \\
(1984) \text {, Ezzamel } \\
(1990) .\end{array}$ \\
\hline $\begin{array}{l}\text { Variáveis } \\
\text { contingenciais }\end{array}$ & Estrutura & $\begin{array}{l}1 \text { Número de trabalhadores } \\
2 \text { Contratação de trabalhadores } \\
3 \text { Horas extras } \\
4 \text { Métodos de seleção de pessoal } \\
5 \text { Métodos de trabalho } \\
6 \text { Decisões de investimentos me- } \\
\text { nores } \\
7 \text { Decisões de investimentos maio- } \\
\text { res }\end{array}$ & $\begin{array}{l}\text { Questões (8 a } 14 \text { ) } \\
\text { Escala Likert } 1 \text { a } 7 \\
\text { (baixa autoridade } \\
\text { - alta autoridade }\end{array}$ & $\begin{array}{l}\text { Gerdin (2005); } \\
\text { Miller } \\
\text { e Droge (1985). }\end{array}$ \\
\hline
\end{tabular}




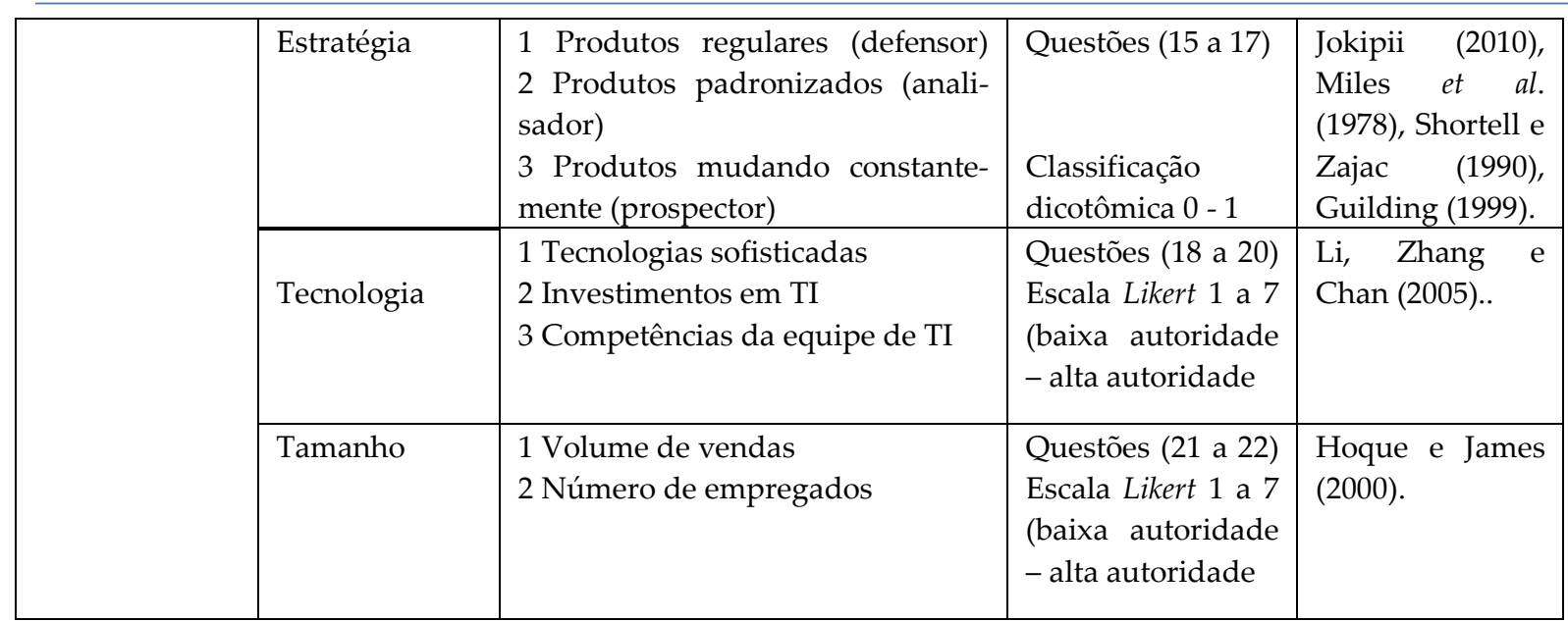

Fonte: Elaboração própria.

No Quadro 1 é possível observar o constructo sobre as variáveis que envolvem a Teoria da Contingência, sobre a qual são estudados a estrutura; estratégia; tecnologia; tamanho e incerteza ambiental aplicadas ao ramo supermercadista Além das variáveis contingenciais, esta pesquisa estudou algumas dimensões do SCG. No Quadro 2, é possível observar essas dimensões.

Quadro 2: Constructo da pesquisa referente aos Sistemas de Controle Gerencial

\begin{tabular}{|c|c|c|c|c|c|}
\hline Variáveis & Dimensões & Subvariáveis & $\begin{array}{l}\text { Questões do instrumento de pes- } \\
\text { quisa }\end{array}$ & Medidas & Autores \\
\hline \multirow[t]{3}{*}{ SCG } & $\begin{array}{l}\text { Cultura } \\
\text { orgânica } \\
\text { inovadora }\end{array}$ & $\begin{array}{ll}\text { Medição } & \text { da } \\
\text { cultura } & \text { de } \\
\text { inovação } & \end{array}$ & $\begin{array}{l}1 \text { Ênfase na busca de consenso, } \\
\text { tomada de decisão participativa } \\
\text { dos funcionários } \\
2 \text { Ênfase na adaptação, sem preo- } \\
\text { cupação com a prática anterior. } \\
3 \text { Ênfase na iniciativa, adaptação } \\
\text { para a situação local ao invés de } \\
\text { coordenação em nível de especia- } \\
\text { lização } \\
4 \text { Fácil acesso informal aos superi- } \\
\text { ores hierárquicos } \\
5 \text { Incentivados a desenvolver no- } \\
\text { vas ideias, mesmo se elas estão } \\
\text { fora da sua área ou da área de } \\
\text { responsabilidade do gestor } \\
6 \text { Gerentes compartilham informa- } \\
\text { ções com os colegas } \\
7 \text { Reação rápida para aproveitar } \\
\text { oportunidades inesperadas }\end{array}$ & 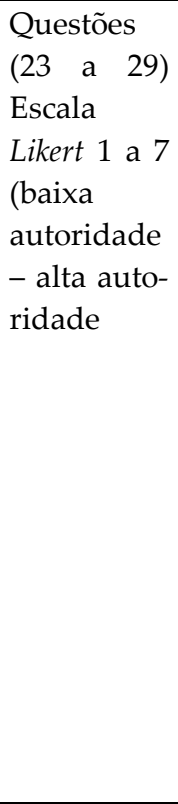 & $\begin{array}{l}\text { Khandwalla, } \\
\text { (1972); } \\
\text { Chenhall; } \\
\text { Morris, } \\
\text { (1995); } \\
\text { Beuren; Oro, } \\
\text { (2014). }\end{array}$ \\
\hline & $\begin{array}{l}\text { Controles } \\
\text { formais }\end{array}$ & $\begin{array}{l}\text { Uso dos con- } \\
\text { troles formais }\end{array}$ & $\begin{array}{l}1 \text { Custo padrão e análise de varia- } \\
\text { ções } \\
2 \text { Orçamento tradicional ou flexí- } \\
\text { vel } \\
3 \text { Custeio baseado em atividades } \\
4 \text { Controle de inventário } \\
5 \text { Avaliação sistemática de gestão } \\
\text { de pessoas }\end{array}$ & 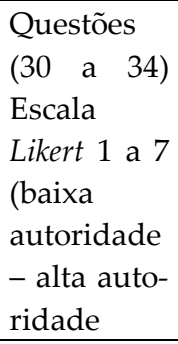 & $\begin{array}{l}\text { Khandwalla, } \\
\text { (1972); } \\
\text { Chenhall; } \\
\text { Morris, } \\
\text { (1995); } \\
\text { Beuren; Oro, } \\
\text { (2014). }\end{array}$ \\
\hline & $\begin{array}{l}\text { Estratégia } \\
\text { de diferen- } \\
\text { ciação }\end{array}$ & $\begin{array}{l}\text { Em relação } \\
\text { aos principais } \\
\text { concorrentes }\end{array}$ & $\begin{array}{l}1 \text { Preço de venda do produto } \\
2 \text { Destina percentual das vendas } \\
\text { para P\&D } \\
3 \text { Destina percentual das vendas } \\
\text { para o marketing } \\
4 \text { Qualidade do produto }\end{array}$ & 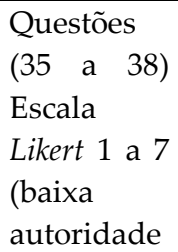 & $\begin{array}{l}\text { Govindara- } \\
\text { jan, (1988); } \\
\text { Beuren; Oro, } \\
(2014) . \text {. }\end{array}$ \\
\hline
\end{tabular}




\begin{tabular}{|l|l|l|l|l|l|}
\hline & & & $\begin{array}{l}\text { - alta auto- } \\
\text { ridade }\end{array}$ \\
\hline
\end{tabular}

Fonte: Adaptado de Chenhall et al. (2011); Beuren e Oro (2014).

No Quadro 2 tem-se o constructo referente aos sistemas de controle gerencial que contempla as dimensões: cultura orgânica inovadora, controles formais e estratégia de diferenciação. O questionário foi adaptado de pesquisas realizadas por Khandwalla (1972), Chenhall e Morris (1995) e Govindarajan (1988), as questões que foram traduzidas por Beuren e Oro (2014) e adaptadas pelo autor.

As questões sobre as dimensões do SCG foram adaptadas do artigo de Beuren e Oro (2014) que utilizaram a pesquisa realizada por Chenhall et al. (2011), e, após a tradução, adaptaram-se a linguagem e as escalas.

Para a análise dos dados, primeiramente os dados foram organizados no Google Docs para a coleta das informações e posteriormente tabulados e calculados em planilhas eletrônicas do $M i$ crosoft Excel. Após codificação das respostas, os dados foram analisados por meio da técnica estatística de consenso e estatística descritiva.

Dallabona (2014) utilizou a técnica de consenso para analisar as variáveis contingenciais, estilos de liderança, folga de recursos (humano, espaço físico, tempo) e folga orçamentária de indústrias têxteis do Sul do Brasil. Pasquali e Vesco (2016) também utilizaram o consenso para analisar a percepção dos contadores quanto à ética profissional e à responsabilidade civil em face da vigência do novo código civil brasileiro.

O estudo desenvolvido por Marcilio, Dallabona e Pletsch (2017) também fez uso da técnica de consenso para analisar a percepção dos gestores de empresas têxteis sediadas no Alto Vale do Itajaí/SC em relação aos componentes de controle interno, o que demonstra que a técnica vem sendo gradativamente utilizada para analisar a percepção e consenso de respondentes em relação à determinadas indagações, como é proposto pelo objetivo deste estudo, fato que justifica a utilização desta técnica $\mathrm{O}$ consenso serve para analisar de forma geral se a opinião dos respondentes é semelhante e é calculado por meio da expressão:

$$
\operatorname{Cns}(x)=1+\sum_{i=0}^{n} P i \log _{2}\left(1-\frac{\left|X_{i}-\mu_{x}\right|}{d_{x}}\right)
$$

Em que:

X é uma variável ordinal (questão);

pi é o percentual associado a cada $\mathrm{X}_{\mathrm{i}}$;

$d_{x}$ é a amplitude da escala,

$\mu_{x}$ é a média das escalas utilizadas

Tastle e Wierman (2007) destacam que o consenso apresenta a opinião de um grupo de pessoas, já o dissenso destaca uma diferença de opinião, causando conflito no grupo. Assim, o Consenso pode ser interpretado da seguinte forma:

Quadro 3: Interpretação do consenso

\begin{tabular}{|c|c|}
\hline Intervalo & Classificação do Consenso \\
\hline CONS $(X)>91 \%$ & Consenso Muito Forte \\
\hline $81 \%<\operatorname{CONS}(X)<90 \%$ & Consenso Forte \\
\hline $61 \%<\operatorname{CONS}(X)<80 \%$ & Consenso Moderado \\
\hline
\end{tabular}




\begin{tabular}{|c|c|}
\hline $41 \%<\operatorname{CONS}(\mathrm{X})<60 \%$ & Equilíbrio \\
\hline $21 \%<\operatorname{CONS}(\mathrm{X})<40 \%$ & Dissenso Moderado \\
\hline $10 \%<\operatorname{CONS}(\mathrm{X})<20 \%$ & Dissenso Forte \\
\hline CONS $(\mathrm{X})<10 \%$ & Dissenso Muito Forte \\
\hline
\end{tabular}

Fonte: Wierman, Tastle $(2005,2007)$.

Questões que obtinham respostas entre os intervalos de consenso, com valor igual a 20\%; igual a $40 \%$ e assim sucessivamente, eram caracterizadas como dissenso moderado, equilíbrio, etc. Além da técnica estatística de consenso os resultados foram analisados por estatística descritiva, com apresentação de percentuais e médias.

\section{DESCRIÇÃO E ANÁLISE DOS DADOS}

Esta seção apresenta o consenso dos líderes/gestores sobre as variáveis contingenciais e SCG pertinentes à gestão organizacional. Os envolvidos foram diretores, gerentes, supervisores, coordenadores e outras atividades de liderança de distintos departamentos das empresas estudadas. Assim, expõe a caracterização dos respondentes, percepções dos líderes em relação às variáveis contingenciais e percepção dos líderes em relação aos sistemas de controle gerencial.

\subsection{Caracterização dos respondentes}

Essa parte da análise apresenta a caracterização dos respondentes, a fim de identificar os padrões de idade, gênero, função, setor, tempo de empresa, escolaridade, área e função exercida na empresa. A Tabela 2 demonstra a caracterização dos respondentes quanto ao gênero, idade, formação acadêmica, tempo de empresa, setor de atuação e função.

Tabela 2: Perfil dos respondentes

\begin{tabular}{|c|c|c|c|}
\hline \multicolumn{2}{|c|}{ Descrição dos itens analisados } & Quantidade de respondentes & $\%$ \\
\hline \multirow{3}{*}{ Gênero } & Feminino & 56 & 44,44 \\
\hline & Masculino & 70 & 55,56 \\
\hline & Total & 126 & 100 \\
\hline \multirow{5}{*}{ Idade } & Entre 16 e 24 anos & 45 & 35,71 \\
\hline & Entre 25 e 30 anos & 25 & 19,84 \\
\hline & Entre 31 e 35 anos & 29 & 23,02 \\
\hline & Acima de 36 anos & 27 & 21,43 \\
\hline & Total & 126 & 100 \\
\hline \multirow{8}{*}{ Formação acadêmica } & Ensino fundamental incompleto & 6 & 4,76 \\
\hline & Ensino fundamental completo & 8 & 6,35 \\
\hline & Ensino médio incompleto & 12 & 9,52 \\
\hline & Ensino médio completo & 54 & 42,86 \\
\hline & Graduação & 32 & 25,40 \\
\hline & Pós-graduação/especialização & 14 & 11,11 \\
\hline & Mestrado/Doutorado & - & - \\
\hline & Total & 126 & 100 \\
\hline \multirow{8}{*}{ Tempo de empresa } & Até 5 anos & 79 & 62,70 \\
\hline & De 6 a 10 anos & 30 & 23,81 \\
\hline & De 11 a 15 anos & 6 & 4,76 \\
\hline & De 16 a 20 anos & 9 & 7,14 \\
\hline & Acima de 21 anos & 2 & 1,59 \\
\hline & Total & 126 & 100 \\
\hline & Açougue & 7 & 5,56 \\
\hline & Comercial/Cadastro & 11 & 8,73 \\
\hline
\end{tabular}




\begin{tabular}{|c|c|c|c|}
\hline \multirow{11}{*}{ Setor de atuação } & Faturamento/Supply & 17 & 13,49 \\
\hline & Financeiro & 13 & 10,32 \\
\hline & FLV & 6 & 4,76 \\
\hline & Frente de Caixa/Loja & 38 & 30,16 \\
\hline & Limpeza & 1 & 0,79 \\
\hline & Manutenção & 3 & 2,38 \\
\hline & Marketing & 1 & 0,79 \\
\hline & Padaria & 9 & 7,14 \\
\hline & $\mathrm{RH}$ & 11 & 8,73 \\
\hline & $\mathrm{TI}$ & 9 & 7,14 \\
\hline & Total & 126 & 100 \\
\hline \multirow{6}{*}{ Função } & Diretor & 10 & 7,94 \\
\hline & Gerente & 7 & 5,56 \\
\hline & Supervisor & 15 & 11,90 \\
\hline & Coordenador & 10 & 7,94 \\
\hline & Outras atividades & 84 & 66,67 \\
\hline & Total & 126 & 100 \\
\hline
\end{tabular}

Fonte: Dados da pesquisa.

É possível observar que o gênero masculino (70 respondentes) tem maior quantidade de respondentes em relação ao feminino (56 respondentes). Isso vai de acordo com o estudo de Lanza e Lana (2011) no qual o gênero masculino se sobrepõe ao feminino. Quanto à idade dos respondentes foi possível constatar que $35,71 \%$ apresentam ter entre 16 e 24 anos, em contrapartida entre 25 e 30 anos está o menor número de respondentes (25), equivalendo a 19,84\% do total.

A formação dos respondentes também foi quesito de análise, pois a formação dos gestores diz muito a respeito da visão da empresa. Percebe-se que $25,4 \%$ dos respondentes possuem formação acadêmica, e um pouco menos da metade possui alguma especialização sendo 11,11\% o que equivale a 14 pessoas. Apenas 6 respondentes possuem o ensino fundamental incompleto, o que não os torna incapazes ou piores que os outros. Os dados convergem com o estudo apresentado por Lanza e Lana (2011) no qual mais de $25 \%$ possui formação acadêmica.

Constata-se que em relação ao tempo em que atuam nas empresas, 79 (setenta e nove respondentes) trabalham a menos de 5 anos, o que equivale a $62,7 \%$. O resultado converge com o apresentado por Sant'anna et al. (2011) no qual a amostra apresentava tempo de empresa inferior a 5 anos. Já 30 (trinta) respondentes atuam nas empresas entre 6 a 10 anos, 6 (seis) de 11 a 15 anos, 9 (nove) de 16 a 20 anos e apenas 2 respondentes estão a mais de 21 anos. Em um ramo tão competitivo, é necessário o aperfeiçoamento contínuo, tanto para os gestores experientes, como aos novos.

Quanto à área de atuação e função, constata-se que 30,16\% dos respondentes atuam no setor de Frente de Caixa/Loja, o qual obtém um contato direto com o cliente. Com 17 respostas, o setor de Faturamento/Supply representa 13,49\% do total de respondentes, setor este que desempenha uma função crucial no segmento da empresa, entretanto não há uma interação direta com o público alvo. O setor de marketing e limpeza contam com os menores indicadores, sendo apenas 0,79\% da população.

Referente a "Outras Atividades" tem-se frete com 66,67\% da amostra pesquisada. Essa função não representa falta de grau de liderança e sim funções não destacadas no trabalho, tais como líder de padaria, líder de estoque etc. A função de diretor apresentou 7,94\% dos 126 respondentes, e estes constituem o quadro de donos das organizações pesquisadas.

\subsection{Percepções dos líderes em relação às variáveis contingenciais}

Neste ponto da análise é dado enfoque às variáveis contingenciais. Existem várias formas de organizar a empresa, entretanto será o ambiente organizacional que definirá qual o melhor estilo. Não existe uma formula única que se encaixa em todos os casos, o que é eficaz em uma unidade 
pode não ser em outra (Betts, 2011). No estudo foram abordadas as variáveis de incerteza, estrutura, estratégia, tecnologia e tamanho. Na Tabela 3 é possível observar a percepção dos líderes em relação à variável contingencial incerteza ambiental.

Tabela 3: Consenso dos líderes em relação a variável contingencial Incerteza

\begin{tabular}{l|c|c|c|c|c|c|c}
\hline & INCERT1 & INCERT2 & INCERT3 & INCERT4 & INCERT5 & INCERT6 & INCERT7 \\
\hline Média & 4,08 & 4,38 & 3,83 & 4,58 & 4,96 & 4,50 & 4,77 \\
Consenso & $56 \%$ & $56 \%$ & $61 \%$ & $59 \%$ & $64 \%$ & $65 \%$ & $59 \%$ \\
Total & 2,29 & 2,45 & 2,32 & 2,69 & 3,18 & 2,93 & 2,82 \\
\hline
\end{tabular}

Fonte: Dados da pesquisa.

Analisando os dados da Tabela 3, que dizem respeito à Incerteza, percebe-se um consenso moderado nas questões INCERT3, INCERT5 e INCERT6, as quais relatam sobre demandas dos clientes, mudanças na legislação (governo) e globalização, respectivamente. Em contrapartida nas INCERT2 "ações dos concorrentes", INCERT4 "disponibilidade de crédito/taxas de juros" e INCERT7 "momento econômico" se tem um consenso de equilíbrio.

Com isso, percebe-se uma atenção dos gestores às incertezas externas, a fim de evitar possíveis problemas futuros, concordando com o que destaca Khandwalla (1972) ao mencionar da importância de se observar a concorrência e o uso de controles gerenciais, o que faz com que os supermercados permaneçam atentos às influências que o ambiente externo provoca internamente nas empresas. Govindarajan (1984) caracteriza a incerteza ambiental como imprevisível em relação às ações dos clientes, fornecedores e entidades reguladores que fazem parte do ambiente externo da empresa. No ramo pesquisado vale destacar principalmente a INCERT1, a qual tratava da incerteza quanto às ações dos fornecedores seja na hora de entregar a mercadoria, na negociação do preço ou até mesmo no pagamento do boleto.

Os resultados são convergentes com o que Govindarajan (1984) informa a respeito da incerteza ambiental, pois nem sempre é fácil identificar os gostos e preferências dos clientes, o que desencadeia uma incerteza em relação ao ambiente externo aos supermercados analisados. Na Tabela 4 se observa a opinião dos líderes em relação à variável contingencial Estrutura.

Tabela 4: Consenso dos líderes em relação a variável contingencial Estrutura

\begin{tabular}{l|c|c|c|c|c|c|c}
\hline & ESTR1 & ESTR2 & ESTR3 & ESTR4 & ESTR5 & ESTR6 & ESTR7 \\
\hline Média & 3,31 & 2,82 & 3,21 & 3,06 & 3,94 & 2,93 & 2,61 \\
Consenso & $37 \%$ & $38 \%$ & $38 \%$ & $37 \%$ & $41 \%$ & $40 \%$ & $48 \%$ \\
Total & 1,23 & 1,07 & 1,20 & 1,11 & 1,62 & 1,18 & 1,26 \\
\hline
\end{tabular}

Fonte: Dados da pesquisa.

É possível constatar um dissenso moderado em relação as 4 perguntas iniciais (ESTR1, ESTR2, ESTR3, ESTR4). Essa baixa no consenso explica-se pelo motivo de que estas questões tratam sobre a autoridade para a tomada de decisões, tais como métodos de seleção, quantidades de horas extras, número de colaboradores necessários e contratação de novos funcionários. Essas funções são desempenhadas pelos profissionais de recursos humanos, que representam "apenas" $8,73 \%$ da amostra pesquisada, o que justifica os percentuais, porém não demonstra a necessidade de exclusão da variável analisada do estudo, pois outras pesquisas podem utilizar-se desta variável para fins comparativos e verificar se o comportamento é similar, tendo em vista as especificidades de cada organização, com base no pressuposto da Teoria da Contingência.

Com um consenso de 48\%, a questão ESTR7 "Investimentos maiores ou de alto valor" diferencia-se um pouco das demais. Apesar dos respondentes terem autoridade na empresa em seus respectivos setores e função, os resultados apontam que os líderes dos diferentes setores não possuem consenso forte sobre a autoridade para tomada de decisões que envolvem investimentos de 
alto valor, pois pressupõem que estas decisões são repassadas aos diretores, para que façam os respectivos investimentos com base nos relatórios e decisões repassadas pelos responsáveis dos setores analisados.

Na Tabela 5 é possível observar o consenso dos líderes em relação à variável contingencial Tecnologia. Referente à tecnologia, as empresas vêm investindo no aperfeiçoando da estrutura para um melhoramento dos serviços e satisfação dos usuários. Kalagnanam e Lindsay (1998) definem a variável contingencial tecnologia como conhecimento, ferramentas, técnicas e ações utilizadas para converter insumos em produtos.

Tabela 5: Consenso dos líderes em relação a variável contingencial Tecnologia

\begin{tabular}{l|c|c|c}
\hline & TEC1 & TEC2 & TEC3 \\
\hline Média & 5,10 & 4,44 & 5,14 \\
Consenso & $70 \%$ & $63 \%$ & $73 \%$ \\
Total & 3,59 & 2,79 & 3,74 \\
\hline
\end{tabular}

Fonte: Dados da pesquisa.

Percebe-se que as 3 (três) questões apresentam um consenso moderado, com maior destaque para TEC3 "nossa equipe de TI é competente na resolução de problemas e criação de facilidades", na qual em uma escala Likert de 1 a 7 pontos a média dos respondentes foi 5,14. Os resultados das variáveis Estrutura e Tecnologia vão de acordo com o que preconiza Woodward (1958), de que o sucesso de uma organização depende da combinação certa dessas duas variáveis, o que pressupõe que os supermercados demonstram combinar as duas variáveis (estrutura e tecnologia) nas atividades organizacionais para auxiliar nas decisões gerenciais e estratégicas.

Analisando as respostas da questão TEC1 "a nossa empresa utiliza tecnologias sofisticadas para o atendimento e prestação de serviços", demonstrando consenso na opinião dos respondentes de que utilizam tecnologias nas atividades, porém pressupõe que no ramo supermercadista não há a necessidade de tecnologia de última geração.

Já em TEC2 "nossa empresa tem investido uma parcela significativa das vendas em TI", como o ramo supermercadista trabalha com alta quantidade de vendas, mas a margem líquida não é alta, pressupõe-se que os líderes não acreditam que os investimentos de parte do faturamento em TI venham a ser relevantes, fato que se comprovou nas demais questões envolvendo a variável contingencial tecnologia para o ramo supermercadista. Na sequência caracteriza-se a variável contingencial estratégia, envolvendo a estratégia defensora, prospectora e analisadora.

Miles et al. (1978) destacam que uma organização de estratégia defensora está focada em defender seus mercados, impedindo que concorrentes se aloquem e tentem buscar seu público alvo. Eles fazem isso por meio de preços competitivos, produtos de alta qualidade, além de outras ações econômicas. O prospector é o oposto do defensor, buscando novos mercados, novos produtos, a fim de estar sempre inovando e buscando novos caminhos. Para que isso seja possível, os prospectores acompanham tendências e estão sempre analisando ambientes para encontrar oportunidades potenciais. Já o analisador é um misto, uma mistura das estratégias defensora e prospectora. Uma organização analisadora busca minimizar o risco para maximizar a oportunidade de lucro.

Tabela 6: Variável contingencial Estratégia

\begin{tabular}{l|c|c}
\hline & Quantidade de respondentes & $\%$ \\
\hline Defensora & 1 & 0,8 \\
Analisadora & 53 & 42,1 \\
Prospectora & 72 & 57,1 \\
\hline Total & 100 & 100 \\
\hline
\end{tabular}

Fonte: Dados da pesquisa. 
Para a variável contingencial Estratégia utilizou-se variável dicotômica (0-1), não sendo possível calcular o consenso dos respondentes. Optou-se em apresentar essa variável de forma descritiva. Para tanto, observou-se que, dos 126 respondentes, 57,1\%, ou seja, 72 respondentes acreditam que a estratégia da organização seja prospectora, enquanto 42,1\% (53) acreditam que a estratégia seja analisadora e apenas $0,8 \%$ (1) respondente acredita que a organização tenha uma estratégia defensora.

Os resultados mostram que os supermercados têm uma estratégia prospectora, conforme sugerem Miles et al. (1978), ou seja, demonstram buscar constantemente a expansão dos supermercados e a inovação de produtos e processos. Na sequência caracterizam-se a variável contingencial tamanho.

Tabela 7: Variável contingencial Tamanho

\begin{tabular}{c|c|c}
\hline Número de Unidades & Faturamento total das 7 & Número de Funcionários \\
\hline 7 & $\mathrm{R} \$ 20.788 .599,91$ & 525 \\
\hline \multicolumn{2}{|c}{ Fonte: Dados da pesquisa. }
\end{tabular}

Conforme dados financeiros e de funcionários disponibilizados pela rede, optou-se em apresentar a variável Tamanho de forma descritiva. As variáveis utilizadas para mensurar o tamanho da empresa foi o Faturamento bruto das unidades matrizes em um total de 7 (sete), com um faturamento superior a 20 milhões de reais e até o dia da coleta de dados um total de 525 funcionários, o qual não participaram totalmente na pesquisa, pois nem todos possuem um cargo de liderança.

Segundo Ezzamel (1990) as atribuições dos gestores estão diretamente ligadas ao tamanho da organização, juntamente com os modelos de SCG definidos por ela, pressupondo que os gestores dos supermercados tenham atribuições específicas para liderar as ações que são projetadas, o que faz com que os líderes tenham maior responsabilidade ao se deparar com diferentes variáveis contingenciais em situações similares à outras redes supermercadistas Na sequência será analisado a percepção dos líderes em relação aos sistemas de controle gerencial.

\subsection{Percepção dos líderes em relação aos sistemas de controle gerencial}

Nessa parte da análise destaca-se a percepção dos líderes em relação aos sistemas de controle gerencial analisados: cultura orgânica inovadora; controles formais e estratégia de diferenciação. Na Tabela 8 apresenta-se o consenso dos líderes em relação ao SCG cultura orgânica inovadora.

Tabela 8: Consenso dos líderes em relação ao sistema de controle gerencial Cultura orgânica inovadora

\begin{tabular}{l|c|c|c|c|c|c|c}
\hline & CUL1 & CUL2 & CUL3 & CUL4 & CUL5 & CUL6 & CUL7 \\
\hline Média & 5,04 & 4,69 & 4,78 & 5,26 & 5,06 & 5,00 & 5,52 \\
Consenso & $69 \%$ & $70 \%$ & $68 \%$ & $68 \%$ & $66 \%$ & $58 \%$ & $68 \%$ \\
Total & 3,49 & 3,29 & 3,25 & 3,57 & 3,34 & 2,92 & 3,74 \\
\hline
\end{tabular}

Fonte: Dados da pesquisa.

O controle da cultura é projetado para afetar e regular o comportamento das pessoas na realização de estratégias e metas da organização (Mintzberg, Ghoshal \& Quinn, 1998). Assim, é possível observar na Tabela 9 um consenso em equilíbrio e moderado para o SCG Cultura orgânica inovadora. Na questão CUL6 "gerentes compartilham informações com os colegas" observa-se um consenso menor em relação às outras, fato este que demonstra que nem sempre os gerentes repas- 
sam informações aos subordinados, seja por questões culturais ou pelo estilo do líder, o que pode afetar no entendimento das estratégias e metas que são traçadas pela gerência.

A questão CUL7 "reação rápida para aproveitar oportunidades inesperadas", é a pergunta que possui a maior média $(5,52)$ e um consenso moderado. Em CUL1 "ênfase na busca de consenso, tomada de decisão participativa dos funcionários", para os gestores é essencial a tomada de decisão participativa, pois boas oportunidades não aparecem ao acaso. É preciso reação rápida para aproveitá-las.

Esses resultados são concernentes ao que destacam Machado, Carvalho e Heizmann (2012), que especificam que a cultura pode ser impactada por diferentes aspectos da configuração organizacional, e que a interação tecnológica dos atores organizacionais pode resultar em novas formas de comunicação e expressão nos negócios. Na Tabela 9 é apresentado o consenso dos líderes em relação ao sistema de controle gerencial dos Controles formais.

Tabela 9: Consenso dos líderes em relação ao sistema de controle gerencial controles formais

\begin{tabular}{l|c|c|c|c|c}
\hline & CTRL1 & CTRL2 & CTRL3 & CTRL4 & CTRL5 \\
\hline Média & 4,94 & 4,92 & 4,90 & 5,50 & 5,22 \\
Consenso & $69 \%$ & $72 \%$ & $67 \%$ & $63 \%$ & $67 \%$ \\
Total & 3,40 & 3,54 & 3,29 & 3,45 & 3,48 \\
\hline
\end{tabular}

Fonte: Dados da pesquisa.

Na percepção dos líderes é fundamental e de vital importância o controle de inventário, seja ele fiscal ou físico, de forma a ter um controle de estoque, o qual lhe dará segurança para vendas, controle de compras etc. Essa análise confirma-se com o consenso da questão CTRL4 "controle de inventário". A questão CTRL4 vai de acordo com o que preconiza Chenhall et al. (2011), quando citam que a integração dos controles formais, do planejamento e do orçamento pode contribuir com a inovação, o que pode ser atrelado aos supermercados analisados, como, por exemplo, identificando novas oportunidades de negócios, motivando as pessoas por meio de recompensas ou apontando falhas no planejado. As questões CTRL1 "custo padrão e análise de variações", CTRL2 "orçamento tradicional ou flexível", CTRL3 "custeio baseado em atividades" possuem consensos moderados.

Chenhall et al. (2011) constataram que a estratégia de diferenciação está altamente ligada com a inovação de produtos/serviços. Sendo assim, incentivam de forma massiva as empresas a implementarem culturas orgânicas inovadoras e controles formais. O estudo de Chenhall está alinhado com o que Chandler (1962) preconiza, de que o desenho do SCG deve ser adaptado para que a estrutura siga a estratégia, pois a estratégia de diferenciação demanda uma política de inovação. Assim, a Tabela 10 descreve o sistema de controle gerencial no que se refere a Estratégia de diferenciação, tendo sido utilizada escala Likert de 7 pontos, de irrelevante até muito relevante para os quesitos apontados na percepção dos respondentes.

Tabela 10: Consenso dos líderes em relação ao sistema de controle gerencial Estratégia de diferenciação

\begin{tabular}{l|c|c|c|c}
\hline & ESTRD1 & ESTRD2 & ESTRD3 & ESTRD4 \\
\hline Média & 5,74 & 3,93 & 5,12 & 6,34 \\
Consenso & $67 \%$ & $56 \%$ & $64 \%$ & $78 \%$ \\
Total & 3,84 & 2,20 & 3,27 & 4,97 \\
\hline
\end{tabular}

Fonte: Dados da pesquisa.

A Tabela 10 mostra um consenso de equilíbrio e moderado. Percebe-se uma variação de consenso entre ESTRD1 "preço de venda do produto", ESTRD2 "destina percentual das vendas para P\&D". Na concepção dos gestores destinar percentual específico do faturamento com P\&D 
não é necessário no ramo supermercadista devido ao fato do setor trabalhar com a revenda de mercadoria e não com produção.

Os resultados alcançados em P\&D referem-se à satisfação de clientes, qualidade dos produtos oferecidos, entrega direta de promoções etc. Já em ESTRD3 “destina percentual das vendas para o marketing", tem-se um consenso moderado superior a ESTRD2 tendo em vista que existe uma maior necessidade no setor supermercadista de atrair clientes, fazer ações promocionais, ações interativas entre membros do grupos e clientes etc.

Por fim identificam-se as duas questões de maior destaque, ESTRD1 "preço de venda do produto" com um consenso de 67\% e ESTRD4 "qualidade do produto" com 78\% de consenso, confirmando que o preço de venda precisa ser competitivo ao mercado. Entretanto, a qualidade desse produto é ainda mais importante, pois não é saudável para organização praticar um preço muito baixo, pois irá afetar seus resultados e ela irá oferecer um produto de qualidade inferior aos concorrentes. Assim pressupõe que a qualidade do produto/serviço dos supermercados é o item mais importante de estratégia e diferenciação, conforme preconiza Chandler (1962).

\section{CONSIDERAÇÕES FINAIS E RECOMENDAÇÕES}

Com objetivo de analisar a percepção dos líderes em relação as variáveis contingenciais e os Sistemas de Controle Gerencial predominantes em uma rede de supermercados do Sul do Brasil, o estudo envolveu 126 respondentes de 7 supermercados, sendo diretores, gerentes, supervisores, coordenadores e outras atividades de liderança em determinados departamentos das empresas estudadas.

Acredita-se, com base nos resultados, que variáveis contingenciais internas e externas impactam na gestão organizacional destes supermercados, demonstrando que, dependendo da situação em que se encontram, precisam remodelar as estratégias e decisões para alcançar os resultados projetados. Os dados sugerem que os clientes, ações dos fornecedores, governo e o momento econômico prevalecem no quesito de incerteza que os líderes têm do mercado, haja vista que nem sempre é possível prever as adaptações que serão necessárias frente às alterações propostas por estas esferas.

Constatou-se com o desenvolvimento do estudo que há uma estrutura descentralizada nos supermercados analisados, as decisões de contratações dos colaboradores, métodos de seleção de pessoal, necessidades de trabalhos extraordinários nem sempre são tomadas pelos gestores, pois pressupõe que há o setor de recursos humanos, responsável pelas decisões que se referem aos funcionários. Também pode se constatar que a tecnologia é combinada com a estrutura organizacional para utilização nas atividades operacionais, como o controle de estoques, caixas, controles financeiros, administrativos, etc. o que pressupõe que não há altos investimentos em tecnologia de ponta.

É possível sugerir que os supermercados são de médio e grade porte, e utilizam-se de estratégia prospectora, ou seja, buscam sempre inovar nos produtos que são oferecidos ao mercado, bem como investem constantemente em propagandas para atrair clientes. Esse fato é relevante para a área de supermercados, uma vez que para atrair clientes é necessário investir em propaganda e publicidade, e sempre buscar oferecer produtos que satisfaçam as preferências de diferentes estilos e gostos de clientes.

Observou-se também que os supermercados possuem uma cultura gerencial ativa, sugerindo ênfase nas adaptações necessárias para melhoria continua dos produtos oferecidos, detém rápida reação para aproveitar as oportunidades que são oferecidas pelo ambiente, principalmente no que se refere às variáveis externas às empresas, como a incerteza ambiental com enfoque para a Teoria da Contingência. Um ponto negativo é que os gerentes não costumam compartilhar infor- 
mações com os colegas, o que acaba gerando assimetria de informações, o que pode dificultar no entendimento das metas a serem alcançadas pela equipe de trabalho.

Utilizar orçamento e planejamento faz com que os supermercados possam se organizar para melhorias em suas atividades, como o processo de inovação na rede supermercadista. Esse fato foi constatado nos supermercados, pois observou-se que utilizam orçamento tradicional e buscam sempre por inovação dos produtos. Focam em marketing para atrair clientes e investem uma parcela em P\&D visando analisar a satisfação dos clientes, a qualidade dos produtos e promoções. Acredita-se que os supermercados analisados possuem um controle gerencial ativo e estão atentos às novas tendências do mercado, agilizando sempre os processos, diminuindo custos e atraindo nova clientela.

Observou-se como fator limitador a importância dos fatores humanos, ou seja, a liderança, principalmente a forma que os gestores tomam as decisões, uma vez que correspondem a uma parcela pequena da população. Assim, recomenda-se a análise de estilos de liderança que possam interferir na escolha e utilização de sistemas gerenciais, bem como a análise de outras variáveis contingenciais que possam influenciar a gestão organizacional, como a cultura organizacional. Outra limitação decorre do segmento analisado, demonstrando que seria interessante analisar empresas familiares do mesmo segmento, com intuito de identificar se estas também possuem descentralização de tarefas, uma vez que os donos tendem a centralizar as informações e a tomada de decisões.

\section{REFERÊNCIAS}

Aguiar, A., B., Pace, E. S. U., \& Frezatti, F. (2009). Análise do Inter-relacionamento das Dimensões da Estrutura de Sistemas de Controle Gerencial: um Estudo Piloto. RAC-Eletrônica, 3(1), 1-21.

Anthony, R. N. \& Govindarajan, V. (2008). Sistemas de Controle Gerencial. 12 ed. São Paulo: McGraw Hill Brasil.

Beuren, I. M., \& Oro, I. M. (2014). Relação entre estratégia de diferenciação e inovação, e sistemas de controle gerencial. Revista de Administração Contemporânea, 18(3), 285-310.

Betts, S. C. (2011). Contingency theory: science or technology? Journal of Business E Economics Re$\operatorname{search}(J B E R), 1(8)$.

Burns, T. E., \& Stalker, G. M. (1961). The management of innovation. University of Illinois at UrbanaChampaign's Academy for Entrepreneurial Leadership Historical Research Reference in Entrepreneurship.

Bruns, W. J. \& Waterhouse, J. H. (1975). Budgetary Control and Organization Structure. Journal of Accounting Research, 13(2), 177-203.

Chandler, A. (1962). Strategy and structure. Cambridge. MA, MIT Press.

Chenhall, R. H. (2003). Management control systems design within its organizational context: findings from contingency-based research and directions for the future. Accounting, Organizations and Society, 28, 127-168.

Chenhall, R. H., Kallunki, J-P., \& Silvola, H. (2011). Exploring the relationships between strategy, innovation, and management control systems: the roles of social networking, organic innovative culture, and formal controls. Journal of Management Accounting Research, 23(1), 99-128. 
Chenhall, R. H., \& Morris, D. (1995). Organic decision and communication processes and management accounting systems in entrepreneurial and conservative business organizations. Omega, 23(5), 485-497.

Child, J.(1975). Managerial and organizational factors associated with company performance-Part 11. A contingency analysis. Journal of Management Studies, 12(1-2), 12-27.

Dallabona, L. F. (2014). Influência de variáveis contingenciais na relação do estilo de liderança à folga organizacional em indústrias têxteis de Santa Catarina. Tese (Doutorado em Ciências Contábeis e Administração).Universidade Regional do Blumenau, Blumenau.

Donaldson, L. (2015). Structural Contingency Theory. School of Management, UNSW-Business School, University of New South Wales, Sydney, NSW, Australia. International Encyclopedia of the Social \& Behavioral Sciences, 2(23), 609-614.

Ein-dor, P., \& Segev, E. (1978). Organizational context and the success of management information systems. Management Science, 24(10), 1064-1077.

Ewusi-mensah, K. (1981). The external organizational environment and its impact on management information systems. Accounting, Organizations and Society, 6(4), 301-316.

Ezzamel, M. (1990). The impact of environmental uncertainty, managerial autonomy and size on budget characteristics. Management Accounting Research, 1(3), 181-197.

Fagundes, J. A., Petri M., Lavarda, R. B., Rodrigues, M. R., Lavarda, C. E. F. \& Soller C. C. (2010). Estrutura organizacional e gestão sob a ótica da teoria da contingência. Gestão e Regionalidade, 26(78), 52-63.

Gerdin, J. (2005). Management accounting system design in manufacturing departments: an empirical investigation using a multiple contingencies approach. Accounting, Organizations and Society, 30(2), 99-126.

Gomes, J. S. (1997). Controle gerencial na era da globalização. Contabilidade Vista E Revista, 8(2), 26-36.

Gordon, L. A. \& Narayanan, V. K. (1984). Management accounting systems, perceived environmental uncertainty and organization structure: an empirical investigation. Accounting, Organizations and Society, 9(1), 33-47.

Govindarajan, V. (1984). Appropriateness of accounting data in performance evaluation: an empirical examination of environmental uncertainty as an intervening variable. Accounting, Organizations and Society, 9(2), 125-135.

Govindarajan, V. (1988). A contingency approach to strategy implementation at the business-unit level: integrating administrative mechanisms with strategy. Academy of management Journal, 31(4), 828-853.

Greiner, L. E. (1972). Evolution and revolution as organizations grow. Harvard Business Review, $50(4), 1-12$.

Guilding, C. (1999). Competitor-focused accounting: an exploratory note. Accounting, Organizations and Society, 24(7), 583-595.

Haldma, T. \& Lääts, K. (2002). Contingencies influencing the management accounting practices of Estonian manufacturing companies. Management Accounting Research, 13, 379-400. 
Henry, J. F. (2006). Management control systems and strategy: A resource-based perspective. Accounting, Organizations and Society, 31(6), 529-558.

Hoque, Z., \& James, W. (2000). Linking balanced scorecard measures to size and market factors: impact on organizational performance. Journal of management accounting research, 12(1), 1-17.

Hoque, Z. (2004). A contingency model of the association between strategy, environmental uncertainty and performance measurement: impact on organizational performance. International Business Review, 13(4), 485-502.

Jokipii, A. (2010). Determinants and consequences of internal control in firms: a contingency theory based analysis. Journal of Management \& Governance, 14(2), 115-144.

Junqueira E. R. de M. (2010). Perfil do sistema de controle gerencial sob a perspectiva da teoria da contingência. Tese de Doutorado. Universidade de São Paulo.

Kalagnanam, S. S., \& Lindsay, R. M. (1998). The use of organic models of control in JIT firms: generalising Woodward's findings to modern manufacturing practices. Accounting, Organizations and Society, 24(1), 1-30.

Kewley, T. H. (1966). Book review: industrial organization: theory and practice. Journal of Industrial Relations, 8(2), 207-208.

Khandwalla, P. N. (1972). The effect of different types of competition on the use of management controls. Journal of Accounting Research, 10(2), 275-285.

LANGFIELD-SMITH, K. (1997). Management control systems and strategy: a critical review. Accounting, Organizations and Society, 22(2), 207-232.

Lanza, F. M., \& Lana, F. C. F. L. (2011). O processo de trabalho em hanseníase: tecnologias e atuação da equipe de saúde da família. Texto and Contexto Enfermagem, 20, 238.

Li, H., Zhang, Y., \& Chan, T. S. (2005). Entrepreneurial strategy making and performance in China's new technology ventures-the contingency effect of environments and firm competences. The Journal of High Technology Management Research, 16(1), 37-57.

Machado, D. D. P. N., De Carvalho, L. C., \& Heinzmann, L. M. (2012). Ambiente favorável ao desenvolvimento de inovações e cultura organizacional: integração de duas perspectivas de análise. Revista de Administração, 47(4), 715-729.

Malmi, T., \& Brown, D. A. (2008). Management control systems as a package-Opportunities, challenges and research directions. Management accounting research, 19(4), 287-300.

Marcilio, V. N., Dallabona, L. F. \& Pletsch, C. S. (2017). Componentes de controle interno: percepção dos gestores de empresas têxteis. Anais do Congresso Internacional de Administração, Ponta Grossa, PR, Brasil.

Marginson, D. Ew. (2002). Management control systems and their effects on strategy formation at middle-management levels: evidence from a UK organization. Strategic management journal, 23(11), 1019-1031.

Merchant, K. A. (1981). The design of the corporate budgeting system: influences on managerial behavior and performance. Accounting Review, 56(4), 813-829. 
Merchant, K. A. (1984). Influences on departmental budgeti ng: an empirical examination of a contingency model. Accounting, Organizations and Society, 9(3-4), 291-307.

Miles, R. E., Snow, C. C., Meyer, A. D., Coleman JR., \& H. J. (1978). Organizational strategy, structure, and process. Academy of Management Review, 3(3), 546-562.

Mintzberg, H., Ghoshal, S., \& Quinn, J. B. (1998) The strategy process. Harlow, Financial Times Prentice Hall.

Molinari, S. K. R. \& Guerreiro, R. (2004). Teoria da contingência e contabilidade gerencial: um estudo de caso sobre o processo de mudança na controladoria do Banco do Brasil. Anais do Congresso USP, São Paulo, SP, Brasil

Morgan, P. G. (1996). Imagens da organização. São Paulo: Atlas.

Oliveira, D. P. R. (2008). Teoria geral da administração. São Paulo: Atlas.

Otley, D. T. (1980). The contingency theory of management accounting: achievement and prognosis. Accounting, Organizations and Society, 5(4), 413-428.Pasquali, K. S. \& Vesco, D. G. D. (2016). Responsabilidade Civil do Contador: Estudo sob Enfoque do Novo Código Civil de 2002 na Perspectiva da Ética Profissional. Contabilidade, Gestão e Governança, 19(2), 292-316.

Pletsch, C. S. Sistemas de controle gerencial e as suas contribuições para o equilíbrio das tensões dinâmicas sob o enfoque da teoria contingencial. Dissertação de Mestrado em Ciências Contábeis, Universidade Regional de Blumenau, SC, Brasil.

Porter, M. E. (1994). Estratégia competitiva: técnicas para análise de indústrias e da concorrência. Tradução: E. M. BRAGA. 8. ed. Rio de Janeiro: Campus.

Simons, R. (1987). Accounting control systems and business strategy: anempirical an alysis. Accounting, Organizations and Society, 12(4), 357-374.

Simons, R. (1990). The role of management control systems in creating competitive advantage: new perspectives. Springer US.

Simons, R. (1995). Levers of control. Boston: Harvard Business School Press.

Veiga-Neto, A. R. \& Souza, T. (2012). Práticas estratégicas em pequenos supermercados na percepção do consumidor de baixa renda. Revista Brasileira de Estratégia, 5(3), 283-293.

Wierman, M. J., \& Tastle, W. J. (2005). Consensus and dissention: theory and properties. Fuzzy Information Processing Society NAFIPS 2005. Annual Meeting of the North American, 75-79.

Wright, P., Kroll, M. J. \& Parnell, J. (2007). Administração estratégica: conceitos. Atlas.

Waterhouse, J. H.; Tiessen, P. (1978). A contingency framework for management accounting systems research. Accounting, Organizations and Society, 3(1), 65-76.

Woodward, J. (1958). Management and technology, 3. HM Stationery Off. 